\title{
PENGARUH MANAJEMEN MODAL KERJA DAN LIKUIDITAS TERHADAP PROFITABILITAS PADA PERUSAHAAN MANUFAKTUR DI SUBSEKTOR KERAMIK, KACA DAN PORSELIN YANG TERDAFTAR DI BURSA EFEK INDONESIA PERIODE 2009-2016
}

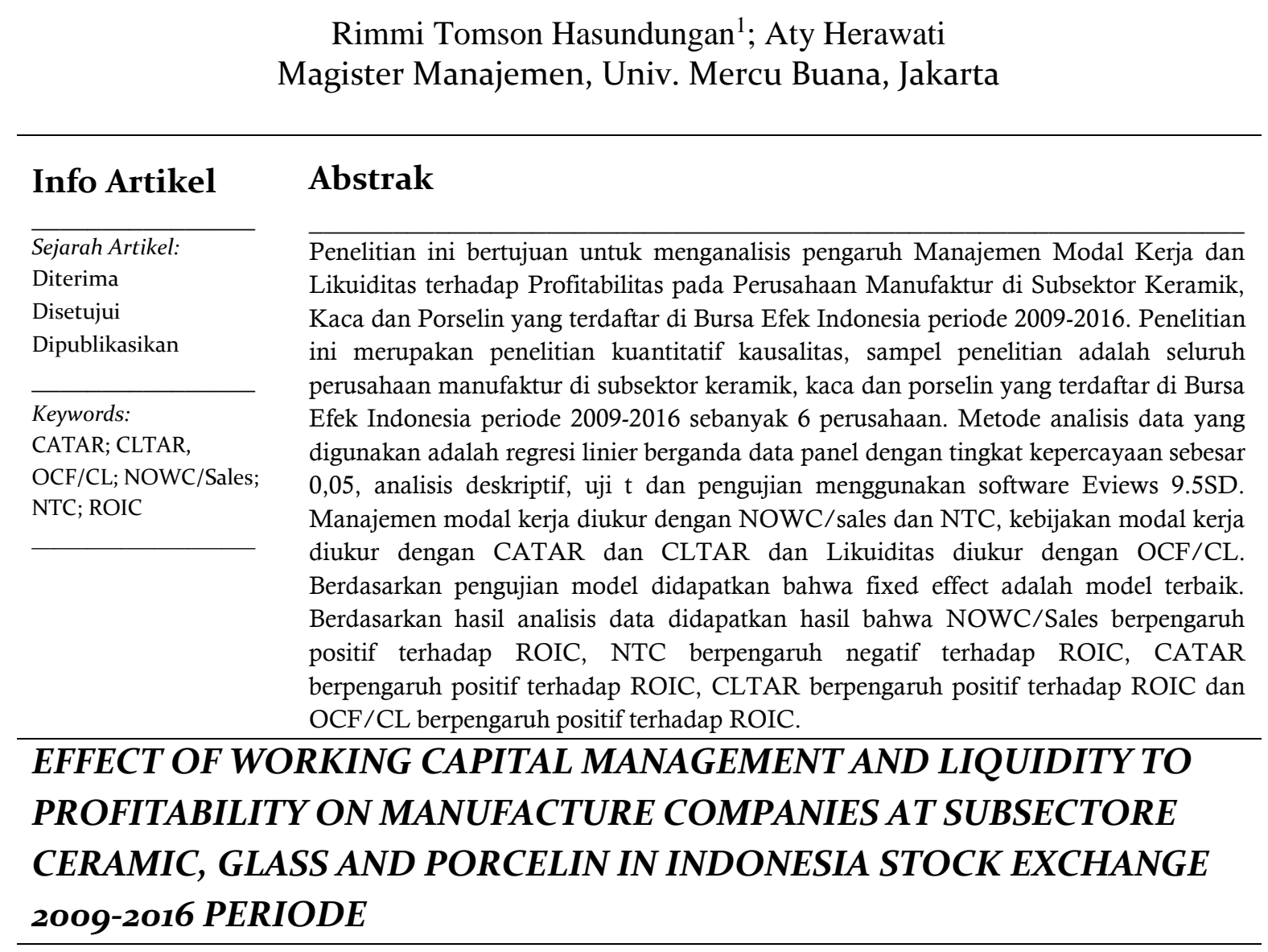

\section{Abstract}

This study aims to examine and analyze the effect of Working Capital and Liquidity on the Performance Manufacture Company on Subsectore Keramik, Kaca and Porcelin in Indonesia Listed Company period 2009-2016. This study is quantitative causality methode, with sample used to all manufacture company on Subsectore Ceramic, Glass amd Porceline in Indonesia Listed Company period 2009-2016 amounted to 6 companies. Data analysis model uses multiple linier regression panel data with level of confidence at 0,05, descriptive statistics, $t$ test and examined using by software Eviews 9.5SD. Working capital management measured by NOWC/Sales and NTC, working capital management policy measured by CATAR and CLTAR, and liquidity measured by OCF/CL. Based on the results model analysis found that fixed effect model is the best on this study. Based on the results found that there is negative relationship NTC on ROIC, positive relationship NOWC/Sales on ROIC, positive relationship CATAR on ROIC, positive relationship CLTAR on ROIC and positive relationship OCF/CL on ROIC. 


\section{PENDAHULUAN}

Sektor properti di Indonesia mengalami pertumbuhan yang cukup pesat seiring dengan meningkatnya pendapatan perkapita masyarakat Indonesia yang diikuti dengan peningkatkan kebutuhan perumahan untuk pemukiman, kegiatan bisnis, maupun investasi. Pertumbuhan properti ini berdampak ikut mendongkrak pertumbuhan industri pendukung diantaranya industri subsektor keramik, kaca dan porselin.

Analisis dilakukan pada sektor industri dasar dan kimia dengan membandingkan profitabilitas antar subsektor dalam sektor industri dasar dan kimia dari tahun 2009-2016. Indikator profitabilitas yang digunakan, diukur dengan Return on Invested Capital (ROIC). ROIC adalah suatu ukuran seberapa besar perusahaan menghasilkan tingkat pengembalian pada modal yang diinvestasikan pada suatu investasi (Damodaran, 2007., Schembs, 2013). Berdasarkan analisis, tren perkembangan ROIC dari tahun 2009-2016 subsektor semen, subsektor keramik, kaca dan porselin, subsektor baja dan produk aplikasi, subsektor kimia, subsektor pakan ternak dan subsektor industri kayu menunjukkan tren penurunan, namun tren penurunan yang paling signifikan adalah pada subsektor keramik, kaca dan porselin. Pada tahun 2009, subsektor keramik, kaca dan porselin mampu menghasilkan ROIC sebesar 55,47\% namun perkembangan untuk tahun-tahun berikutnya mengalami penurunan hingga pada tahun 2016 hanya mampu menghasilkan ROIC sebesar -24,88\%. Subsektor ini mengalami keterpurukan dibandingkan subsektor lainnya. Berikut disajikan gambar perbandingan ROIC antar subsektor periode tahun 2009-2016.

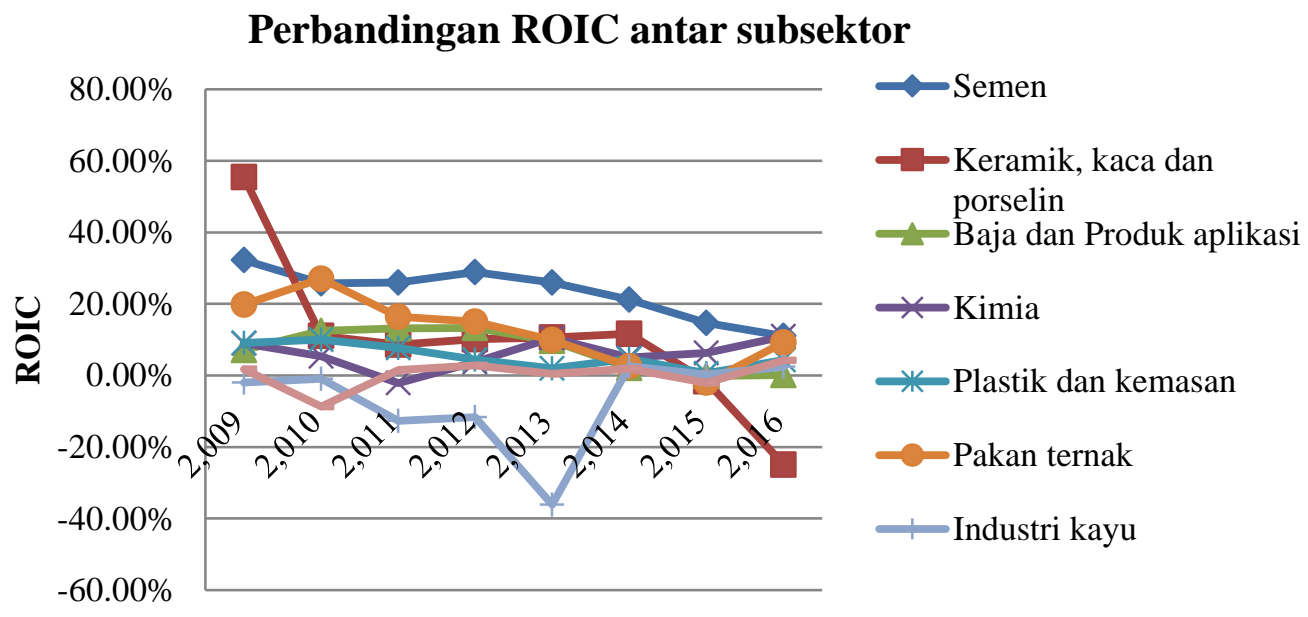

Gambar 1. Perbandingan ROIC antar Subsektor dalam Sektor Industri Dasar dan Kimia.

Sumber : Laporan Tahunan Perusahaan, IDX, Diolah Penulis

Tren penjualan industri subsektor keramik, kaca dan porselin yang terdaftar di Bursa Efek Indonesia dari tahun 2009-2016 menunjukkan kenaikan, namun bila dilihat dari tren laba setelah pajak dari tahun 2009-2016 menunjukkan penurunan. Dengan penurunan laba berdampak pula terhadap penurunan tingkat ROIC. 
Berikut ini disajikan grafik perkembangan penjualan dan laba (rugi) agregat perusahaan subsektor keramik, kaca dan porselin untuk periode 2009-2016.

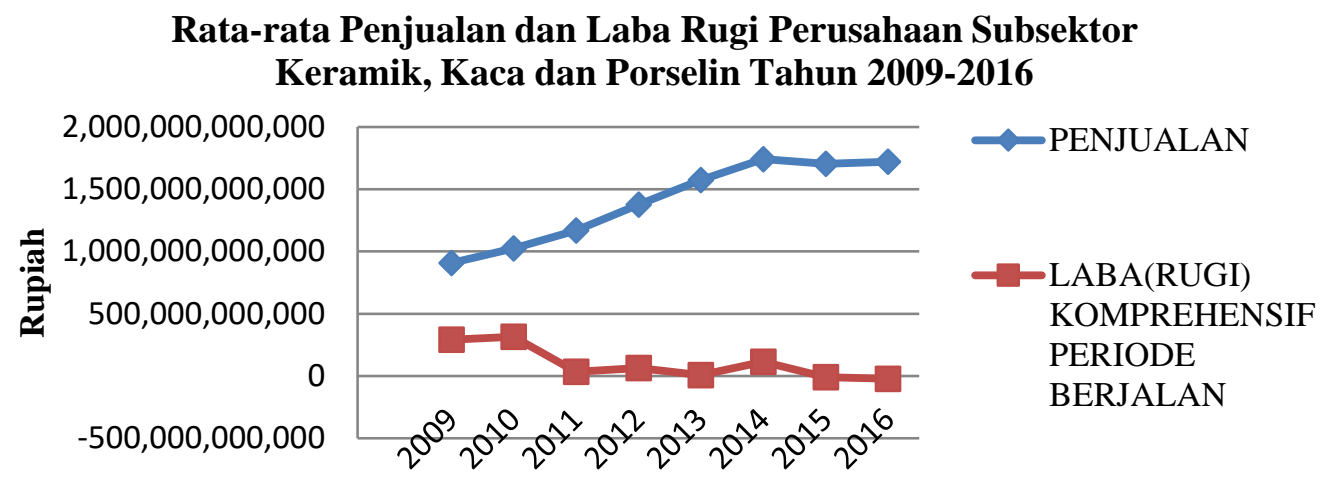

Gambar 2. Perkembangan Rata-rata Penjualan dan Laba (Rugi) Perusahaan Subsektor Keramik, Kaca dan Porselin Periode 2009-2016

Sumber : Laporan Tahunan Perusahaan, IDX, Diolah Penulis

Perusahaan mempunyai tujuan untuk dapat mencapai tujuan perusahaan yang telah ditetapkan dalam rencana kerja anggaran perusahaan serta visi dan misi perusahaan. Menurut Ani, Okwo dan Ugwenta (2012), tujuan utama perusahaan adalah untuk memaksimalkan kekayaan para pemegang saham. Cara untuk memaksimalkan kekayaan shareholder yaitu dengan cara memaksimalkan profit perusahaan. Penelitian menunjukkan manajemen modal kerja yang baik pada suatu perusahaan dapat meningkatkan profitabilitas perusahaan (Puraghajan, Ramzani, dan Bin, 2014., Ngendakumana, Jagero dan Gondo, 2015., Sudiyatno, Puspitasari dan Sudarsi, 2017).

Tujuan dari manajemen modal kerja adalah memastikan bahwa perusahaan mampu melanjutkan operasional dan memiliki kemampuan yang cukup untuk memenuhi pelunasan hutang jangka pendek dan biaya operasional yang akan datang dengan cara menjaga kecukupan cash flow (Yakubu, 2017). Lebih lanjut menurut Sudiyatno, Puspitasari dan Sudarsi (2017) menyebutkan manajemen modal kerja menentukan masa depan, kinerja dan pengembangan perusahaan karena manajemen akan terkait terhadap kemampuan perusahaan dalam menjalankan operasionalnya.

Pentingnya manajemen modal kerja karena terkait langsung pada kemampuan perusahaan dalam menghasilkan dan mengelola cash flow. Kemampuan perusahaan dalam menghasilkan kas tergantung pada likuiditas dan profitabilitas (Yilmaz, 2015). Pendapat ini dikonfirmasi oleh Moghadam dan Rahimi (2016), menyatakan bahwa cash flow conversion cycle berpengaruh terhadap profitabilitas. Lavasani, Jabbari, dan Rahmani (2016)., Kroes dan Manikas (2014) menyatakan bahwa strategi manajemen cash flow akan mempengaruhi profitabilitas perusahaan. Penelitian Zeidan dan Shafir (2017) menemukan bahwa peningkatan manajemen modal kerja akan meningkatkan free cash flow to equity, harga saham dan profitabilitas.

Penelitian tentang manajemen modal kerja telah bayak dilakukan dengan berbagai variabel yang diteliti. Terdapat research gap atau ketidak selarasan 
antara penelitian-penelitian terdahulu mengenai pengaruh manajemen modal kerja terhadap profitabilitas. Berdasarkan kajian penelitian terdahulu ditemukan hasil bahwa terdapat pengaruh yang signifikan baik positif maupun negatif, juga pengaruh tidak signifikan antara pengelolaan manajemen modal kerja terhadap profitabilitas. Berikut disajikan research gap variabel-variabel penelitian yang ditemukan.

Tabel 1

Research Gap

\begin{tabular}{cllc}
\hline No & Variabel & \multicolumn{1}{c}{ Hasil } & \multicolumn{1}{c}{ Peneliti } \\
\hline 1. & NOWC/ & Operating Working Capital & Konak dan Guner (2016) \\
& Sales & $\begin{array}{l}\text { to Sales (NOWC/Sales) } \\
\text { tidak berpengaruh terhadap } \\
\text { profitabilitas. }\end{array}$ &
\end{tabular}

2. NTC

NTC berpengaruh positif terhadap profitabilitas.

NTC berpengaruh negatif terhadap profitabilitas.

NTC tidak berpengaruh terhadap profitabilitas.

3. CATAR CATAR berpengaruh positif terhadap profitabilitas.

CATAR berpengaruh negatif terhadap profitabilitas.

CATAR tidak berpengaruh terhadap profitabilitas.

4. CLTAR CLTAR berpengaruh positif terhadap profitabilitas.

CLTAR berpengaruh negatif terhadap profitabilitas.

CLTAR tidak berpengaruh terhadap profitabilitas.
Tahir dan Anuar (2016), Javid (2014), Adebowale (2014)

Hoang (2015), Jahfer (2015)., Shubita (2013)

Dadashi, Asgharian, Naghibi (2016)., Yadav dan Kumar S.B (2014)

Sudiyatno, Puspitasari dan Sudarsi (2017)., Nur, Indrawati dan Ratnawati (2016)., Rais (2016)

Ali dan Ali (2015)., Puraghajan,

Ramzani, Bin (2014)

Jahfer (2015)., Yadav dan Kumar S.B (2014)

Jahfer (2015)., dan Mwangi, Makau dan Kosimbei (2014)., Puraghajan, Ramzani, Bin (2014)

Sudiyatmo, Puspitasari dan Sudarsi (2017)., Rais (2016)., Tahir dan

Anuar (2016)

Nur, Indrawati dan Ratnawati (2016)., Yadav dan Kumar S.B (2014)

Asad dan Qadeer (2014)

$\begin{array}{ll}\text { 5. } \mathrm{OCF} / \mathrm{CL} & \mathrm{OCF} / \mathrm{CL} \text { berpengaruh } \\ \text { terhadap profitabilitas }\end{array}$

Sumber: Studi Pustaka, 2017

Studi pustaka yang dilakukan terhadap pada penelitian-penelitian sebelumnya, variabel terikat yang digunakan lebih banyak memakai ROA, ROE, ROCE, GPM, dll untuk mengukur profitabilitas. Pada penelitian ini penulis tertarik untuk menggunakan ROIC sebagai variabel terikat dalam mengukur kinerja keuangan. ROIC dipakai sebagai ukuran kinerja keuangan karena memiliki beberapa kelebihan dibandingkan dengan variabel-variabel profitabilitas lainnya. Menurut Mauboussin dan Callahan (2014), ROIC memiliki keunggulan 
dibandingkan dengan rasio profitabilitas lainnya karena penggunaan rasio ROIC lebih efektif dan efisien dalam mengukur profitabilitas perusahaan. Kelebihan lain perhitungan menggunakan ROIC dibandingkan dengan ROE adalah ROIC tidak dipengaruhi oleh leverage keuangan dan pembelian kembali saham, sedangkan ROE bervariasi berdasarkan pemilihan struktur perusahaan dan aktivitas pembelian kembali saham perusahaan. ROA memiliki sejumlah ketidak konsistenan antara pembilang dan penyebut sehingga hasilnya tidak dapat diandalkan. Misalkan terjadi perubahan hutang, akan mempengaruhi pembilang yaitu pendapatan sementara aset tidak terjadi dampak proporsial pada penyebut.

\section{TELAAH PUSTAKA}

\section{Teori Keagenan (Agency Theory)}

Teori keagenan pertama kali dikemukakan oleh Jensen dan Meckling pada tahun 1976. Pada teori keagenan (agency theory) dijelaskan bahwa pada sebuah perusahaan terdapat hubungan kontraktual antara prinsipal dan agen (Vernimmen., dkk, 2014). Pemegang saham memberikan mandat kepada manajemen untuk mengelola dana dalam perusahaan yang dipercayakan kepadanya untuk dapat memaksimalkan nilai ekuitas perusahaan, meningkatkan ukuran perusahaan, profitabilitas dan meminimalkan resiko terhadap modal yang diinvestasikan (risk to capital employed) (Vernimmen., dkk, 2014).

\section{Pengaruh Net Operating Working Capital/Sales terhadap Profitabilitas}

Net Operating Working Capital to Sales (NOWC/Sales) menunjukkan jumlah modal kerja yang dibutuhkan untuk menunjang penjualan. Menurut Ehrhardt dan Brigham (2011) menyatakan bahwa dengan penurunan NOWC/Sales akan meningkatkan value perusahaan dan profitabilitas. Penelitian yang dilakukan oleh Konak dan Guner (2016) dengan sampel 29 perusahaan yang terdaftar pada BIST SME Industrial Index periode 2011-2014 menyebutkan bahwa working capital to sales tidak berpengaruh terhadap ROA, ROE dan Net Margin. Berdasarkan uraian tersebut penulis merumuskan hipotesis sebagai berikut:

H1 : NOWC/Sales berpengaruh negatif terhadap ROIC.

\section{Pengaruh Net Trade Cycle terhadap Profitabilitas}

Net Trade Cycle (NTC) menunjukkan jumlah hari penjualan yang dibutuhkan untuk membiayai modal kerja (Rehn, 2012). Penurunan NTC akan mengurangi kebutuhan pendanaan eksternal, biaya pinjaman dan meningkatkan profitabilitas (Rehn, 2012). Penelitian Tahir dan Anuar (2016) menyatakan NTC berpengaruh positif terhadap ROA, Javid (2014) menyatakan bahwa NTC berpengaruh positif terhadap NOP. Adebowale (2014) menyatakan NTC berpengaruh positif terhadap kinerja perusahaan yang diukur dengan Tobin's Q, lebih lanjut Adebowale (2014) manyarankan perusahaan, agar dapat mencapai kinerja yang lebih baik dan memaksimalkan nilai pemegang saham harus dilakukan dengan cara meningkatkan modal kerja melalui meningkatkan NTC sehingga dapat memenuhi kewajiban jangka pendek. 
Namun penelitian Hoang (2015)., Shubita (2013) menyatakan NTC berpengaruh terhadap ROA., Jahfer (2015)., Rehn (2012)., menyatakan NTC berpengaruh negatif terhadap GOP. Kaddumi dan Ramadan (2012)., Vahid, Elham, Mohsen dan Mohammadreza (2012) menyatakan NTC berpengaruh negatif terhadap NOP., Kawadagli (2012) melakukan penelitian terhadap sampel perusahaan kecil dan menengah dan terhadap perusahaan besar, pada perusahaan kecil dan menengah ditemukan bahwa NTC berpengaruh positif terhadap laba operasional sedangkan pada perusahaan besar NTC berpengaruh negatif terhadap laba operasional. Secara keseluruhan sample Karadagli (2012) menemukan bahwa NTC berpengaruh negatif terhadap Operating Income. Berdasarkan uraian tersebut, penulis merumuskan hipotesis sebagai berikut:

$\mathrm{H} 2$ : NTC berpengaruh negatif terhadap ROIC.

\section{Pengaruh Current Asset to Total Asset Ratio terhadap Profitabilitas}

Current Assets to Total Asset Ratio (CATAR) merupakan rasio perbandingan aset lancar terhadap total aset. Semakin tinggi rasio menunjukkan suatu perusahaan menerapkan kebijakan investasi konservatif dalam mengelola modal kerja (Charitou, Lois, dan Christoforou, 2016., Mwangi, Makau dan Kosimbei, 2014). Menurut Horne dan Wachowich (2012)., Ehrhardt dan Brigham (2011) menyatakan perusahaan yang menerapkan kebijakan investasi konservatif akan menurunkan profitabilitas karena dana yang tertanam pada aset lancar tinggi.

Penelitian Sudiyatmo, Puspitasari dan Sudarsi (2017)., Nur, Indrawati dan Ratnawati (2016)., Tahir dan Anuar (2016)., Charitou, Lois dan Christoforou (2015)., Shahzad, Fareed dan Zulfiqar (2015)., Mwangi, Makau dan Kosimbei (2014)., Tufail (2013) menyatakan bahwa CATAR berpengaruh positif terhadap ROA. Rais (2016)., Wijaya (2012) dan Mohamad dan Mohd Saad (2010) menyatakan CATAR berpengaruh positif terhadap ROIC. Kaddumi dan Ramadan (2012) menyatakan CATAR berpengaruh positif terhadap NOP.

Namun penelitian Ali dan Ali (2014) menyatakan CATAR berpengaruh negatif terhadap ROIC. Puraghajan, Ramzani dan Bin (2014) menyatakan CATAR berpengaruh negatif terhadap ROA. Berdasarkan uraian tersebut penulis merumuskan hipotesis sebagai berikut:

H3 : CATAR berpengaruh positif terhadap ROIC.

\section{Pengaruh Current Liabilitas to Total Asset Ratio terhadap Profitabilitas}

Rasio Current Liabilitas to Total Asset Ratio (CLTAR) merupakan rasio perbandingan antara kewajiban jangka pendek terhadap total aset. Semakin tinggi rasio menunjukkan suatu perusahaan menerapkan kebijakan pendanaan agresif modal kerja (Charitou, Lois, dan Christoforou, 2016., Mwangi, Makau dan Kosimbei, 2014). Menurut Horne dan Wachowich (2012)., Ehrhardt dan Brigham (2011) menyatakan perusahaan yang menerapkan kebijakan pendanaan agresif akan menghasilkan profitabilitas yang tinggi namun resiko yang akan dihadapi tinggi pula. Pendanaan yang bersumber dari hutang jangka pendek memiliki biaya bunga yang lebih rendah dibandingkan hutang jangka panjang namun memiliki resiko yang besar jika perusahaan tidak mampu membayar saat jatuh tempo. 
Penelitian Mwangi, Makau dan Kosimbei (2014)., Puraghajan, Ramzani, Bin (2014) menyatakan CLTAR berpengaruh positif terhadap ROA. Puraghajan, Ramzani, Bin (2014) selain meneliti pengaruh CLTAR terhadap ROA juga dilakukan terhadap ROE, dimana didapatkan hasil bahwa CLTAR berpengaruh negatif. Hasil penelitian Puraghajan, Ramzani, Bin (2014) menyimpulkan bahwa strategi agresif modal kerja pada investasi dan pendanaan modal kerja berdampak langsung terhadap ROA dan ROE. Penelitian Jahfer (2015) berpengaruh positif terhadap GOP

Namun penelitian Sudiyatno dan Sudarsi (2017)., Tahir dan Anuar (2016)., Charitou, Lois dan Christoforou (2015)., Ngendakumana, Jagero, dan Gondo (2015) menyatakan CLTAR berpengaruh negatif terhadap ROA. Rais (2016)., Wijaya (2012)., Mohamad dan Saad (2010) menyatakan CLTAR berpengaruh negatif terhadap ROIC. Kaddumi dan Ramadan (2012) menyatakan CLTAR berpengaruh negatif terhadap NOP. Berdasarkan uraian tersebut penulis merumuskan hipotesis sebagai berikut:

H4 : CLTAR berpengaruh negatif terhadap ROIC.

\section{Pengaruh Operating Cash Flow to Current Liabilities terhadap Profitabilitas}

Operating Cash Flow to Current Liabilities (OCF to CL) adalah kemampuan perusahaan untuk membayar kewajiban jangka pendek dari kas yang dihasilkan pendapatan operasional perusahaan (Palepu dan Healy, 2008). Horne dan Wachowicz (2012) menyatakan bahwa likuiditas berbanding terbalik dengan profitabilitas yaitu peningkatan likuiditas akan diikuti dengan penurunan profitabilitas. Lavasani, Jabbari dan Rahmani (2016) melakukan penelitian terhadap efek manajemen cash flow terhadap profitabilitas di Turki menemukan bahwa manajemen cash flow berpengaruh positif terhadap profitabilitas dan nilai perusahaan. Penelitian Asad dan Qadeer (2014) pada sektor minyak dan energi pada Karachi Stock Exchange, Pakistan menemukan bahwa OCF to CL berpengaruh positif terhadap profitabilitas. Berdasarkan uraian tersebut penulis merumuskan hipotesis sebagai berikut:

H5 : OCF/CL berpengaruh positif terhadap ROIC.

\section{Metode}

Jenis penelitian ini merupakan penelitian kuantitatif kausalitas yaitu hubungan sebab akibat dimana terdapat hubungan antara dua variabel atau lebih. Penelitian kuantitatif kausalitas untuk mengetahui pengaruh NOWC/Sales, NTC, CATAR, CLTAR dan OCF/CL terhadap ROIC pada perusahaan manufaktur di Subsektor Keramik, Kaca dan Porselin yang terdaftar di Bursa Efek Indonesia periode 2009-2016.

Variabel dependen penelitian ini adalah profitabilitas yang diukur dengan Return on Invested Capital (ROIC) yang merupakan suatu ukuran seberapa besar perusahaan menghasilkan tingkat pengembalian pada modal yang diinvestasikan pada suatu investasi (Damodaran, 2007, Schembs, 2013). Sedangkan veriabel independen dalam penelitian ini terdiri dari efisiensi modal kerja yang diukur dengan Net Operating Working Capital to Sales (NOWC/Sales) yang mengukur seberapa besar NOWC yang dibutuhkan terhadap penjualan (Palepu dan Healy, 
2008) dan Net Trade Cycle (NTC) yang merupakan jumlah hari penjualan yang dibutuhkan untuk membiayai modal kerja (Jahfer, 2015). Kebijakan manajemen modal kerja yang diukur dengan Current asset to Total Asset Ratio (CATAR) yang merupakan rasio perbandingan antara aset lancar terhadap total aset (Charitou, Lois, dan Christoforou, 2016) dan Current Liabilities to Total Asset Ratio (CLTAR) yang merupakan rasio perbandingan antara kewajiban jangka pendek terhadap total aset (Charitou, Lois, dan Christoforou, 2016). Likuiditas yang diukur dengan Operating Cash Flow to Current Liabilities (OCF/CL) yang merupakan kemampuan perusahaan untuk membayar kewajiban jangka pendek menggunakan kas yang dihasilkan aktivitas operasional perusahaan (Palepu dan Healy, 2008).

Populasi dalam penelitian ini adalah seluruh perusahaan subsektor keramik, kaca dan porselin yang tercatat di Bursa Efek Indonesia (BEI), berdasarkan data terakhir per 31 Desember 2016 sebanyak 6 perusahaan. Teknik penentuan sampel dalam penelitian ini adalah purposive sampling yang didasarkan pada kriteria sebagai berikut: (1) Perusahaan subsektor keramik, kaca dan porselin yang terdaftar pada BEI dari periode Desember 2009 sampai Desember 2016 (2) Perusahaan di subsektor keramik, kaca dan porselin yang terdaftar secara kontiniu di BEI selama periode 2009 sampai 2016 (3) Menerbitkan laporan keuangan lengkap per 31 Desember 2009 sampai dengan 31 Desember 2016. Berdasarkan kriteria tersebut, diperoleh jumlah sampel sebanyak 6 perusahaan dengan jumlah total laporan keuangan sebanyak 48 laporan keuangan.

Teknik analisis data menggunakan analisis statistik deskriptif, unit root test dan regresi data panel. Dalam mekanisme pemilihan model regresi data panel dilakukan uji Chow, uji Hausman dan uji Lagrange Multiplier. Regresi data panel memiliki kelebihan yaitu dengan kombinasi antara time series dengan cross section, data panel lebih informatif, lebih beragam, sedikit kolinearitas antar variabel, meningkatkan tingkat kepercayaan (degrees of freedom) dan lebih efisien (Gujarati., Porter, 2009).

\section{HASIL DAN PEMBAHASAN} Analisis Statistik Deskriptif

Tabel 2

Hasil Statistik Deskriptif

\begin{tabular}{lcccccc}
\hline & ROIC & NOWC_SALES & NTC & CATAR & CLTAR & OCF \\
\hline Minimum & -1.571638 & -1.579441 & 27.01030 & 0.145211 & 0.050644 & -0.273261 \\
Maximum & 2.930033 & 0.726781 & 455.4880 & 0.656378 & 2.020932 & 1.478868 \\
Mean & 0.101274 & 0.185295 & 127.9414 & 0.387036 & 0.294899 & 0.470320 \\
Std. Dev. & 0.498291 & 0.326915 & 85.92052 & 0.137885 & 0.289039 & 0.457935 \\
Observations & 48 & 48 & 48 & 48 & 48 & 48 \\
\hline
\end{tabular}

Sumber: Data Hasil Pengolahan

Pada sampel terdapat perusahaan yang mengalami kerugian dengan ROIC negatif, dengan nilai minimum ROIC yaitu pada IKAI tahun 2016 sebesar $157,16 \%$ dan nilai maximum ROIC pada MLIA pada tahun 2009 sebesar 293\%. Nilai standar deviasi ROIC lebih besar dari nilai rata-rata, menunjukkan bahwa 
variasi ROIC selama periode pengamatan memiliki simpangan sebesar $49,83 \%$ dari nilai rata-rata.

Nilai minimum NOWC/Sales selama periode pengamatan yaitu pada IKAI tahun 2016 sebesar $-157,94 \%$. Nilai maksimum NOWC/Sales selama periode pengamatan yaitu pada IKAI pada tahun 2009 sebesar 72,68\%. Nilai standar deviasi NOWC/Sales sebesar 32,69\% lebih besar dari nilai rata-rata, menunjukkan bahwa variasi NOWC/Sales selama periode pengamatan memiliki simpangan sebesar 32,69 dari nilaai rata-rata.

Nilai minimum NTC selama periode pengamatan yaitu pada MLIA tahun 2016 sebesar 27 hari. Nilai maksimum NTC selama periode pengamatan yaitu pada IKAI pada tahun 2009 sebesar 455,49 hari. Nilai standar deviasi NTC lebih kecil dari nilai rata-rata, hal ini menunjukkan fluktuasi nilai NTC yang kecil pada perusahaan manufaktur disubsektor keramik, kaca dan porselin selama periode tahun 2009-2016.

Nilai minimum CATAR selama periode pengamatan yaitu pada IKAI tahun 2016 sebesar $14,52 \%$ dan nilai maksimum CATAR selama periode pengamatan yaitu pada TOTO tahun 2010 sebesar 65,64\%. Nilai standar deviasi lebih kecil dari nilai rata-rata, hal ini menunjukkan fluktuasi nilai CATAR yang kecil pada perusahaan manufaktur disubsektor keramik, kaca dan porselin selama periode tahun 2009-2016.

Nilai minimum CLTAR selama periode pengamatan yaitu pada KIAS tahun 2012 sebesar 5,06\% dan nilai maksimum CLTAR selama periode pengamatan yaitu pada MLIA tahun 2009 sebesar 202,09\%. Nilai standar deviasi lebih kecil dari nilai rata-rata, hal ini menunjukkan fluktuasi nilai CLTAR yang kecil pada perusahaan manufaktur disubsektor keramik, kaca dan porselin selama periode tahun 2009-2016.

Nilai minimum OCF/CL selama periode pengamatan yaitu pada KIAS tahun 2015 sebesar $-27,33 \%$ dan nilai maksimum OCF/CL selama periode pengamatan yaitu pada AMFG tahun 2010 sebesar 147,89\%. Nilai standar deviasi lebih kecil dari nilai rata-rata, hal ini menunjukkan fluktuasi nilai OCF/CL yang kecil pada perusahaan manufaktur disubsektor keramik, kaca dan porselin selama periode tahun 2009-2016.

\section{Analisis Regresi Data Panel}

Berikut ini disajikan hasil pengolahan analisis regresi linier data panel menggunakan metode model common effect (pooled ordinary least square), fixed effect, dan random effect menggunakan eviews 9.5: 
1. Model common effect

Tabel 3

Hasil Model Common Effect

\begin{tabular}{crrrr}
\hline \hline \multicolumn{1}{c}{ Variable } & Coefficient & Std. Error & t-Statistic & Prob. \\
\hline \hline C & -0.529030 & 0.095320 & -5.550027 & 0.0000 \\
NTC & -0.003019 & 0.000426 & -7.080191 & 0.0000 \\
NOWC_SALES & 1.270488 & 0.118463 & 10.72476 & 0.0000 \\
CATAR & 0.287247 & 0.236123 & 1.216515 & 0.2306 \\
CLTAR & 1.885630 & 0.119608 & 15.76512 & 0.0000 \\
OCF & 0.242064 & 0.080373 & 3.011767 & 0.0044 \\
\hline \hline R-squared & 0.879969 & Mean dependent var & 0.101274 \\
Adjusted R-squared & 0.865680 & S.D. dependent var & 0.498291 \\
S.E. of regression & 0.182622 & Akaike info criterion & -0.446324 \\
Sum squared resid & 1.400739 & Schwarz criterion & -0.212424 \\
Log likelihood & 16.71178 & Hannan-Quinn criter. & -0.357933 \\
F-statistic & 61.58207 & Durbin-Watson stat & 1.379600 \\
Prob(F-statistic) & 0.000000 & & \\
\hline \hline
\end{tabular}

Sumber: Hasil Output Eviews 9.5, 2017

2. Model fixed effect

Tabel 4

Hasil Model Fixed Effect

\begin{tabular}{crcrr}
\hline \hline Variable & Coefficient & Std. Error & t-Statistic & Prob. \\
\hline C & -0.908264 & 0.219504 & -4.137808 & 0.0002 \\
NTC & -0.002267 & 0.000657 & -3.450213 & 0.0014 \\
NOWC_SALES & 1.046834 & 0.133492 & 7.841954 & 0.0000 \\
CATAR & 1.327164 & 0.473706 & 2.801662 & 0.0080 \\
CLTAR & 1.686608 & 0.123855 & 13.61758 & 0.0000 \\
OCF & 0.159542 & 0.081041 & 1.968651 & 0.0565 \\
D1 & 0.084054 & 0.142262 & 0.590835 & 0.5582 \\
D2 & 0.298831 & 0.150813 & 1.981471 & 0.0550 \\
D3 & -0.072162 & 0.178024 & -0.405351 & 0.6876 \\
D4 & 0.050718 & 0.113867 & 0.445411 & 0.6586 \\
D5 & -0.243878 & 0.097816 & -2.493230 & 0.0173 \\
\hline \hline R-squared & 0.917196 & Mean dependent var & 0.101274 \\
Adjusted R-squared & 0.894816 & S.D. dependent var & 0.498291 \\
S.E. of regression & 0.161606 & Akaike info criterion & -0.609258 \\
Sum squared resid & 0.966313 & Schwarz criterion & -0.180441 \\
Log likelihood & 25.62219 & Hannan-Quinn criter. & -0.447208 \\
F-statistic & 40.98365 & Durbin-Watson stat & 1.494090 \\
Prob(F-statistic) & 0.000000 & & \\
\hline \hline
\end{tabular}

Sumber: Hasil Output Eviews 9.5, 2017 
Tabel 5

Hasil Model Random Effect

\begin{tabular}{|c|c|c|c|c|}
\hline Variable & Coefficient & Std. Error & t-Statistic & Prob. \\
\hline $\mathrm{C}$ & -0.529030 & 0.084351 & -6.271783 & 0.0000 \\
\hline NOWC_SALES & 1.270488 & 0.104830 & 12.11946 & 0.0000 \\
\hline NTTC & -0.003019 & 0.000377 & -8.000938 & 0.0000 \\
\hline CATAR & 0.287247 & 0.208950 & 1.374717 & 0.1765 \\
\hline CLTAR & 1.885630 & 0.105843 & 17.81530 & 0.0000 \\
\hline OCF & 0.242064 & 0.071123 & 3.403434 & 0.0015 \\
\hline \multicolumn{5}{|c|}{ Effects Specification } \\
\hline & & & S.D. & Rho \\
\hline Cross-section random & & & $1.86 \mathrm{E}-07$ & 0.0000 \\
\hline Idiosyncratic random & & & 0.161606 & 1.0000 \\
\hline \multicolumn{5}{|c|}{ Weighted Statistics } \\
\hline R-squared & 0.879969 & \multirow{5}{*}{\multicolumn{2}{|c|}{$\begin{array}{l}\text { Mean dependent var } \\
\text { S.D. dependent var } \\
\text { Sum squared resid } \\
\text { Durbin-Watson stat }\end{array}$}} & 0.101274 \\
\hline Adjusted R-squared & 0.865680 & & & 0.498291 \\
\hline S.E. of regression & 0.182622 & & & 1.400739 \\
\hline F-statistic & 61.58207 & & & 1.379600 \\
\hline Prob(F-statistic) & 0.000000 & & & \\
\hline \multicolumn{5}{|c|}{ Unweighted Statistics } \\
\hline R-squared & 0.879969 & \multirow{2}{*}{\multicolumn{2}{|c|}{$\begin{array}{l}\text { Mean dependent var } \\
\text { Durbin-Watson stat }\end{array}$}} & 0.101274 \\
\hline Sum squared resid & 1.400739 & & & 1.379600 \\
\hline
\end{tabular}

Sumber: Hasil Output Eviews 9.5, 2017

\section{Pemilihan Model Regresi Data Panel}

1. Uji Chow

Tabel 6 disajikan hasil uji Chow menggunakan software Eviews 9.5:

\section{Tabel 6 \\ Hasil Uji Chow}

Reaundant Fixed Effects Tests

Equation: EQ02

Test cross-section fixed effects

\begin{tabular}{lrrr}
\hline \hline Effects Test & Statistic & d.f. & Prob. \\
\hline \hline Cross-section F & 3.326823 & $(5,37)$ & 0.0140 \\
Cross-section Chi-square & 17.820837 & 5 & 0.0032 \\
\hline \hline
\end{tabular}

Sumber: Hasil Output Eviews 9.5, 2017

Hasil uji Chow pada tabel 5 menunjukkan p-value cross-section Chi-square sebesar $0,0032<0,05$ dengan taraf signifikansi sebesar 5\%. Hal tersebut 
menunjukan bahwa model fixed effect lebih baik dibandingkan dengan model common effect. Dengan hasil tersebut maka selanjutnya dilakukan uji Hausman, untuk menentukan model terbaik antara model fixed effect atau model random effect.

2. Uji Hausman

Tabel 7 disajikan hasil uji Hausman menggunakan software Eviews 9.5:

\section{Tabel 7}

Hasil Uji Hausman

Correlated Random Effects - Hausman Test

Equation: EQ03

Test cross-section random effects

\begin{tabular}{lrrr}
\hline \hline Test Summary & Chi-Sq. Statistic & Chi-Sq. d.f. & Prob. \\
\hline \hline Cross-section random & 16.634115 & 5 & 0.0052 \\
\hline \hline
\end{tabular}

Sumber: Hasil Output Eviews 9.5, 2017

Hasil Uji Hausman pada tabel 7 menunjukkan p-value cross-section random sebesar $0,0052<0,05$ dengan taraf signifikansi 5\% sehingga bisa kita simpulkan bahwa model fixed effect lebih baik daripada model random effect. Berdasarkan kedua pengujian model tersebut, dapat disimpulkan bahwa model regresi data panel yang sesuai untuk penelitian ini adalah model fixed Effect. Berikut ini adalah bentuk persamaan model fixed effect hasil output Eviews 9.5:

Estimation Equation:

$$
\begin{aligned}
\mathrm{ROIC} & =\mathrm{C}(1)+\mathrm{C}(2) * \mathrm{NTC}+\mathrm{C}(3) * \text { NOWC_SALES + C }(4) * \text { CATAR + C }(5) * \text { CLTAR } \\
& +\mathrm{C}(6) * \mathrm{OCF}+\mathrm{C}(7) * \mathrm{D} 1+\mathrm{C}(8) * \mathrm{D} 2+\mathrm{C}(9) * \mathrm{D} 3+\mathrm{C}(10) * \mathrm{D} 4+\mathrm{C}(11) * \mathrm{D} 5
\end{aligned}
$$

Substituted Coefficients:

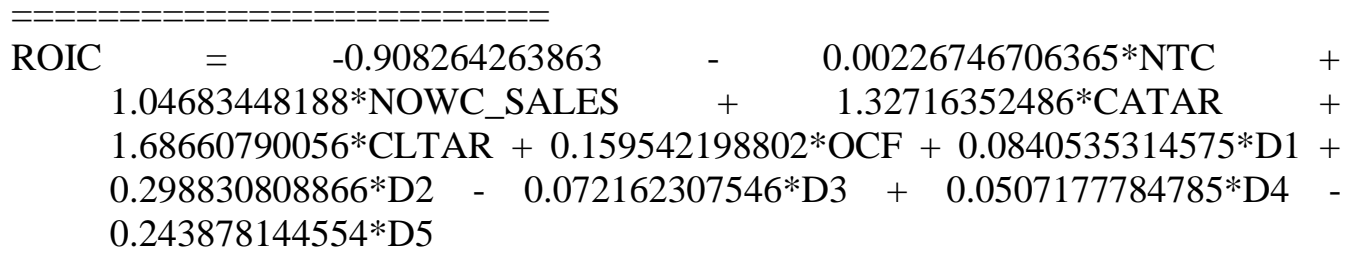

\section{Pembahasan}

Pengaruh Net Operating Working Capital terhadap Return on Invested Capital

Dari Tabel 4 dapat dilihat NOWC/Sales memiliki nilai prob. sebesar 0,0000 yang berada di bawah taraf signifikansi sebesar 0,05 dan koefisien regresi positif sebesar 1,046834. Dengan begitu, keputusan yang diambil adalah menolak Ha1 dan menerima H01, yang berarti NOWC/Sales berpengaruh positif terhadap ROIC. Hasil penelitian ini tidak dapat membuktikan hipotesis yang menyatakan "NOWC/Sales berpengaruh negatif terhadap ROIC". 
Penelitian ini tidak mendukung teori Ehrhardt dan Brigham (2011) yang menyatakan bahwa dengan penurunan NOWC/Sales akan meningkatkan profitabilitas, maupun penelitian Konak dan Guner (2016) menyebutkan bahwa working capital to sales tidak berpengaruh terhadap profitabilitas. Pada penelitian ini ditemukan kondisi bahwa peningkatan NOWC/Sales justru akan meningkatkan ROIC, hal ini dapat disebabkan karena antara lain:

1. Karakteristik perusahaan manufaktur khususnya pada subsektor keramik, kaca dan porselin yang terdiri dari:

a. Bahan baku, sebagian besar bahan baku pada subsektor keramik, kaca dan porselin berasal dari impor yang harganya dipengaruhi oleh kurs dolar. Oleh karena itu agar lebih menguntungkan secara skala ekonomi maka ketika harga dan kurs relatif murah, kecenderungannya adalah membeli persediaan dalam jumlah besar. Disamping itu, harga biaya gas dan listrik pada subsektor ini kira-kira sebesar 25-30\% dari harga pokok produksi sehingga agar secara skala ekonomi lebih murah maka produksi persediaan barang jadi berada pada skala maksimal kapasitas produksi.

b. Memiliki nilai persediaan yang cukup besar yang terdiri dari (a) persediaan bahan mentah, dan (b) persediaan barang jadi, persediaan yang harus selalu ada untuk memungkinkan perusahaan dapat mendukung rencana penjualan. Mempertahankan tingkat persediaan yang tinggi dapat memberikan keuntungan dengan mengurangi biaya interupsi yang mungkin terjadi dalam proses produksi jika tingkat persediaan tidak cukup dan kemungkinan akan kelangkaan produk dan/atau bahan baku, serta perlindungan terhadap fluktuasi harga, dan keuntungan lainnya.

c. Lamanya perputaran modal kerja, Kasmir (2016) menyatakan bahwa waktu produksi mempengaruhi jumlah modal kerja yang dibutuhkan. Semakin lama proses produksi yang dibutuhkan dari bahan baku hingga menjadi persediaan maka berdampak pada besarnya jumlah modal kerja yang dibutuhkan.

d. Kebijakan kredit pembelian dan penjualan, semakin longgar kebijakan kredit penjualan akan mempengaruhi semakin besarnya jumlah modal kerja yang diinvestasikan dalam piutang (Berk dan DeMarco, 2014). Pada subsektor keramik, kaca dan porselin umumnya diberikan pembayaran dengan tempo selama 2-3 bulan, sehingga berakibat pada besarnya investasi modal kerja pada piutang. Pada kondisi ini perusahaan harus mengelola piutang dengan hati-hati agar tidak terjadi piutang macet dengan terus memantau dan melakukan follow up piutang costumer yang akan jatuh tempo dan yang sudah jatuh tempo. Dengan menerapkan prosedur penjualan dengan kredit dan prosedur penagihan yang efektif maka akan meningkatkan penjualan dan mengurangi investasi modal kerja pada piutang. Kebijakan pembelian turut mempengaruhi besarnya jumlah investasi modal kerja pada persediaan, dimana pemasok umumnya memberikan diskon jika melakukan pembayaran lebih cepat atau 
memberikan harga yang lebih kompetitif jika pembelian dalam kuantitas yang besar.

Dari karakteristik industri subsektor ini dapat disimpulkan bahwa pengelolaan modal kerja harus mempertimbangan skala ekonomi agar harga produk yang dihasilkan dapat bersaing, juga harus terus meningkatkan volume penjualan produk. Perbedaan pengaruh NOWC/Sales terhadap profitabilitas pada penelitian ini dibandingkan dengan teori Ehrhardt dan Brigham (2011) maupun penelitian Konak dan Guner (2016) dapat disebabkan oleh faktor karakteristik industri subsektor keramik, kaca dan porselin dapat berbeda dengan subsektor lainnya. Penelitian Ali dan Ali (2014) pada perusahaan yang terdaftar di Karachi Stock Exchange periode 2009-2013, Renh (2012) pada perusahaan yang terdaftar di Swedia dan Finlandia periode 2002-2010 juga menemukan bahwa pengaruh manajemen modal kerja bervariasi antar industri.

2. Pertumbuhan penjualan

Net operating working capital to sales (NOWC/sales) didefenisikan sebagai rasio yang menggambarkan efesiensi manajemen modal kerja yang dibutuhkan untuk menciptakan penjualan (Palepu dan Healy, 2008). Lebih lanjut Damodaran (2014) menyebutkan bahwa kebutuhan modal kerja ditentukan oleh penjualan, dimana permintaan untuk persediaan ditentukan dari jumlah unit yang perusahaan perkirakan akan terjual dan perubahan piutang usaha yang mencerminkan pertumbuhan dari perusahaan. Dari uraian tersebut, dalam rangka menghadapi perkiraan pertumbuhan penjualan periode masa depan, maka perusahaan menerapkan strategi meningkatkan investasi pada NOWC.

Hasil penelitian ini yang menunjukkan bahwa NOWC/Sales berpengaruh positif terhadap ROIC jika dikaitkan dengan teori keagenan yaitu untuk memaksimalkan nilai ekuitas perusahaan, ukuran perusahaan, profitabilitas dan meminimalkan resiko terhadap modal yang diinvestasikan dapat dicapai oleh Manajemen dengan peningkatan NOWC/Sales. Manajemen harus mampu mengelola NOWC/Sales dengan baik untuk mendukung pencapaian profitabilitas yang pada akhirnya meningkatkan tingkat pengembalian investasi pada perusahaan, karena jika tidak kondisi sebaliknya akan terjadi yaitu peningkatan NOWC/Sales justru membawa dampak pada penurunan profitabilitas seperti yang dikemukakan dengan teori Ehrhardt dan Brigham (2011) yang menyatakan bahwa dengan penurunan NOWC/Sales akan meningkatkan profitabilitas.

\section{Pengaruh Net Trade Cycle terhadap Return on Invested Capital}

Dari Tabel 4 dapat dilihat NTC memiliki nilai prob. sebesar 0,0014 yang berada di bawah taraf signifikansi sebesar 0,05 dan koefisien regresi negatif sebesar 0,002267. Dengan begitu, keputusan yang diambil adalah menolak H02 dan menerima Ha2, yang berarti NTC berpengaruh negatif signifikan terhadap ROIC. Hasil penelitian ini dapat membuktikan hipotesis yang menyatakan "NTC berpengaruh negatif terhadap ROIC". Hasil penelitian ini sesuai dengan teori yang 
mengatakan bahwa dengan penurunan umur NTC maka akan berpengaruh meningkatkan profitabilitas, hal ini dikarenakan semakin pendek atau turun umur NTC maka semakin cepat investasi modal kerja perusahaan dikonversi kembali kedalam kas (dimulai dari persediaan dikonversi menjadi penjualan hingga proses penagihan sehingga uang tersebut dapat dipergunakan kembali untuk membayar kewajiban perusahaan saat jatuh tempo dan membiayai operasional perusahaan) yang pada akhirnya akan meningkatkan profitabilitas.

Hasil penelitian ini menunjukkan bahwa NTC berpengaruh negatif terhadap ROIC, jika dikaitkan dengan teori keagenan yaitu untuk memaksimalkan nilai ekuitas perusahaan, ukuran perusahaan, profitabilitas dan meminimalkan resiko terhadap modal yang diinvestasikan dapat dicapai oleh Manajemen dengan penurunan NTC. Penelitian ini mendukung penelitian sebelumnya yang dilakukan oleh Hoang (2015), Jahfer (2015), Shubita (2013), Kaddumi dan Ramadan (2012), Rehn (2012), Vahid, Elham, Mohsen dan Mohammadreza (2012), yang menyatakan bahwa NTC berpengaruh negatif signifikan terhadap profitabilitas. Bukti empiris ini menandakan bahwa hubungan terbalik NTC dengan profitabilitas, dengan penurunan NTC akan meningkatkan profitabilitas . Shubita (2013) menyatakan bahwa hubungan negatif antara NTC dengan profitabilitas dapat dijelaskan dengan kekuatan pasar (market power) atau pangsa pasar (market share). Perusahaan dengan NTC yang lebih rendah memiliki daya tawar (bargaining power) terhadap pemasok dan/atau pelanggan serta memiliki profitabilitas yang lebih tinggi karena menguasai pasar (market dominance) (Shubita, 2013., Shin dan Soenen, 1998). Kaddumi dan Ramadan (2012) menyatakan bahwa NTC memiliki hubungan terbalik dengan profitabilitas sehingga dengan penurunan umur NTC dapat berimplikasi penciptaan penambahan nilai shareholder dengan peningkatan profitabilitas. Hasil penelitian ini tidak mendukung Tahir dan Anuar (2016), Javid (2014), Adebowale (2014) yang menyatakan bahwa NTC berpengaruh positif terhadap profitabilitas.

\section{Pengaruh Current Asset to Total Asset Ratio terhadap Return on Invested Capital}

Dari Tabel 4 dapat dilihat CATAR memiliki nilai prob. sebesar 0,0080 yang berada di bawah taraf signifikansi sebesar 0,05 dan koefisien regresi positif sebesar 1,327164. Dengan begitu, keputusan yang diambil adalah menolak H03 dan menerima Ha3, yang berarti Current Asset to Total Asset (CATAR) berpengaruh positif signifikan terhadap ROIC. Hasil penelitian ini dapat membuktikan hipotesis yang menyatakan "CATAR berpengaruh positif terhadap ROIC". Penelitian ini tidak mendukung teori Horne dan Wachowich (2012)., Ehrhardt dan Brigham (2011) yang menyatakan bahwa perusahaan yang menerapkan kebijakan investasi modal kerja konservatif akan menurunkan 
profitabilitas karena dana yang tertanam pada aset lancar tinggi. Peningkatan aset lancar terhadap total aset (CATAR) mampu mendukung terciptanya penjualan sehingga menyebabkan peningkatan profitabilitas. Jika perusahaan tidak mampu mengkonversi dengan cepat investasi aset lancar menjadi penjualan dan kas, berdasarkan bukti empiris pada penelitian ini, perusahaan subsektor keramik, kaca dan porselin akan mengalami kerugian. Disamping itu, hasil penelitian ini menunjukkan bahwa semakin perusahaan menerapkan kebijakan investasi modal kerja yang konservatif akan memiliki profitabilitas yang lebih tinggi.

Hasil penelitian ini bahwa CATAR berpengaruh positif terhadap ROIC, jika dikaitkan dengan teori keagenan yaitu untuk memaksimalkan nilai ekuitas perusahaan, ukuran perusahaan, profitabilitas dan meminimalkan resiko terhadap modal yang diinvestasikan dapat dicapai oleh Manajemen dengan peningkatan CATAR. Hasil penelitian ini mendukung penelitian sebelumnya yang dilakukan oleh Sudiyatno, Puspitasari dan Sudarsi (2017), Nur, Indrawati dan Ratnawati (2016), Rais (2016), Tahir dan Anuar (2016), Charitou, Lois dan Christoforou (2015), Shahzad, Fareed dan Zulfiqar (2015), Mwangi, Makau dan Kosimbei (2014), Tufail (2013), Kaddumi dan Ramadan (2012), Wijaya (2012), Mohamad dan Saad (2010) yang menyatakan bahwa CATAR berpengaruh positif terhadap profitabilitas. Namun berbeda dengan penelitian yang dilakukan oleh Ali dan Ali (2015), Puraghajan, Ramzani dan Issa (2014) menyatakan CATAR berpengaruh negatif terhadap profitabilitas.

\section{Pengaruh Current Liabilities to Total Asset Ratio terhadap Return on Invested Capital}

Dari Tabel 4 dapat dilihat CLTAR memiliki nilai prob. sebesar 0,0000 yang berada di bawah taraf signifikansi sebesar 0,05 dan koefisien regresi postif sebesar 1,686608. Dengan begitu, keputusan yang diambil adalah menolak $\mathrm{Ha} 4$ dan menerima H04, yang berarti Current Liabilities to Total Asset (CLTAR) berpengaruh positif signifikan terhadap ROIC. Hasil penelitian ini tidak dapat membuktikan hipotesis yang menyatakan "CLTAR berpengaruh negatif terhadap ROIC". Hasil penelitian ini sesuai dengan teori Horne dan Wachowich (2012)., Ehrhardt dan Brigham (2011) yang menyatakan bahwa perusahaan yang menerapkan kebijakan pendanaan agresif akan menghasilkan profitabilitas yang tinggi. Penelitian ini menunjukkan bahwa perusahaan yang menerapkan kebijakan pendanaan modal kerja agresif maka akan berdampak meningkatkan profitabilitas. Hasil penelitian ini dapat disimpulkan bahwa penggunaan kewajiban jangka pendek untuk membiayai aset lebih baik dari pada penggunaan hutang jangka panjang, hal ini disebabkan karena biaya hutang jangka pendek lebih rendah dibandingkan dengan penggunaan hutang jangka panjang.

Hasil penelitian ini bahwa CLTAR berpengaruh positif terhadap ROIC jika dikaitkan dengan teori keagenan yaitu bahwa untuk memaksimalkan nilai ekuitas perusahaan, ukuran perusahaan, profitabilitas dan meminimalkan resiko terhadap modal yang diinvestasikan dapat dicapai oleh Manajemen dengan peningkatan 
CLTAR. Strategi meningkatkan CLTAR menunjukkan bahwa manajemen menggunakan strategi pendanaan agresif untuk menunjang peningkatan profitabilitas yaitu dengan menggunakan pendanaan yang berasal dari hutang dagang dan hutang bank jangka pendek lebih besar dibandingkan dengan hutang jangka panjang.

Hasil penelitian ini bahwa CLTAR berpengaruh positif terhadap ROIC jika dikaitkan dengan teori keagenan yaitu bahwa untuk memaksimalkan nilai ekuitas perusahaan, ukuran perusahaan, profitabilitas dan meminimalkan resiko terhadap modal yang diinvestasikan dapat dicapai oleh Manajemen dengan peningkatan CLTAR. Strategi meningkatkan CLTAR menunjukkan bahwa manajemen menggunakan strategi pendanaan agresif untuk menunjang peningkatan profitabilitas yaitu dengan menggunakan pendanaan yang berasal dari hutang dagang dan hutang bank jangka pendek lebih besar dibandingkan dengan hutang jangka panjang.

Hasil penelitian ini mendukung penelitian sebelumnya yang dilakukan oleh Jahfer (2015)., Mwangi, Makau dan Kosimbei (2014) dan Puraghajan, Ramzani, Issa (2014) menyatakan CLTAR berpengaruh positif terhadap profitabilitas. Namun berbeda dengan penelitian yang dilakukan oleh Sudiyatno, Puspitasari dan Sudarsi (2017), Rais (2016), Tahir dan Anuar (2016), Charitou, Lois dan Christoforou (2015), Ngendakumana, Jagero, dan Gondo (2015), Kaddumi dan Ramadan (2012), Wijaya (2012)., Mohamad dan Saad (2010) yang menyatakan bahwa CLTAR berpengaruh negatif terhadap profitabilitas.

\section{Pengaruh Operating Cash Flow to Current Liabilities terhadap Return on Invested Capital}

Dari Tabel 4 dapat dilihat OCF/ CL memiliki nilai prob. sebesar 0,0565 yang berada diatas taraf signifikansi sebesar 0,05 namun signifikan pada taraf signifikan sebesar 0,10 dan koefisien regresi positif sebesar 0,159542. Dengan begitu, keputusan yang diambil adalah menolak H05 dan menerima Ha5, yang berarti Operating Cash Flow to Current Liabilities (OCF/CL) berpengaruh positif terhadap ROIC. Hasil penelitian ini dapat membuktikan hipotesis yang menyatakan "OCF/CL berpengaruh positif terhadap ROIC". Hasil penelitian ini tidak mendukung teori Horne dan Wachowicz (2012), yang menyatakan bahwa likuiditas berbanding terbalik dengan profitabilitas, yaitu peningkatan likuiditas diikuti dengan penurunan profitabilitas.

Hasil penelitian ini bahwa OCF/CL berpengaruh positif terhadap ROIC jika dikaitkan dengan teori keagenan yaitu bahwa untuk memaksimalkan nilai ekuitas perusahaan, ukuran perusahaan, profitabilitas dan meminimalkan resiko terhadap modal yang diinvestasikan dapat dicapai oleh Manajemen dengan peningkatan OCF/CL. Perusahaan yang memiliki cash flow operasional besar lebih profit dibandingkan dengan perusahaan dengan cash flow yang lebih kecil. Kondisi ini terjadi karena perusahaan dengan cash flow positif berarti memiliki tingkat likuiditas yang lebih tinggi dibandingkan perusahaan yang memiliki cash flow operasional negatif. Likuiditas yang tinggi yang diukur dengan OCF/CL memberikan keleluasaan dalam melunasi kewajiban jangka pendek yang akan jatuh tempo, membiayai operasional perusahaan sehari-hari dan melakukan 
penambahan investasi, jika dibandingkan dengan perusahaan yang memiliki OCF/CL lebih kecil maupun perusahaan dengan OCF/CL negatif.

Hasil penelitian ini mendukung penelitian sebelumnya yang dilakukan oleh Asad dan Qadeer (2014) pada sektor minyak dan energi di Karachi Stock Exchange (Pakistan) yang menyebutkan bahwa OCF/CL berpengaruh positif terhadap profitabilitas.

\section{PENUTUP}

Berdasarkan hasil penelitian dan pembahasan, maka diambil kesimpulan sebagai berikut: Net Operating Working Capital to Sales (NOWC/Sales) berpengaruh positif terhadap ROIC, Net Trade Cycle (NTC) berpengaruh negatif terhadap Return on Invested Capital (ROIC), Current Asset to Total Asset Ratio (CATAR) berpengaruh positif terhadap ROIC, Current Liabilities to Total Asset Ratio (CLTAR) berpengaruh positif terhadap ROIC. Hasil penelitian ini dapat dipakai para calon investor yang ingin berinvestasi pada perusahaan keramik, kaca dan porselin di Bursa Efek Indonesia hendaknya memperhatikan manajemen modal kerja dan likuiditas dalam pengambilan keputusan investasi terutama variabel NOWC/Sales, NTC, CATAR, CLTAR dan OCF/CL yang mempengaruhi profitabilitas secara signifikan. Bagi manajemen, shareholder dan calon investor dapat menggunakan variabel Return on Invested Capital (ROIC) dalam mengevaluasi profitabilitas, karna lebih efektif dalam mengukur tingkat pengembalian atas modal yang diinvestasikan pada perusahaan tersebut.

Penelitian ini memiliki keterbatasan dimana sample hanya pada subsektor keramik, kaca dan porselin. Bagi peneliti selanjutnya disarankan menggunakan objek penelitian yang berbeda dan menambahkan keputusan investasi jangka panjang yang diukur dengan variabel Fixed Asset to Total Asset (FATA) agar dapat memperkaya wawasan dan menunjang pengembangan teori manajemen terkait pengelolaan manajemen modal, likuiditas, kebijakan investasi jangka panjang sehingga mampu meningkatkan profitabilitas.

\section{DAFTAR RUJUKAN}

Adebowale, N. S. 2014. Effect of Working Capital Management and Financial Constraints on Corporate Performance. Thesis. Sintok: Othman Yeop Abdullah Graduate School of Business. Universiti Utara Malaysia.

Ali, M dan Ali, S. B. 2014. The Impact of Working Capital Management on Firm Protability and Fixed Investment in Pakistan. Munich Personal RePEc Archive. Paper No. 64520: 1-41

Ani, W. U., Okwo, I. M, dan Ugwunta, D. O. 2012. Effects of Working Capital Management on Profitability: Evidence from the Top Five Beer Brewery Firms in the World". Asian Economic and Financial Review. 2(8): 966-982

Asad, M dan Qadeer, H. 2014. Component of Working Capital and Profitability: A case of Fuel and Energy Sector of Pakistan. Paradigms: A Research Journal of Commerce, Economics and Social Sciences. 8(1): 41-45

Berk, J dan Demarzo, P. 2014. Corporate Finance. $3^{\text {rd }}$ edition. Boston: Pearson Education 
Charitou, M., Lois, P, dan Christoforou, A. 2016. The Relationship between Aggressive and Conservative Working Capital. International Journal of Arts and Commerce. 5(5): 143-150

Dadashi, I., Asgharian, A., Naghibi, M.H, dan Abbasifard, S. 2016. The Impact of Net Trade Cycle on Firm Performance in TSE. Journal of productivity and development. 2(2): 36-40

Damodaran, A. 2007. Return on Capital (ROC), Return on Invested Capital (ROIC) and Return on Equity (ROE): Measurement and Implications. diunduh diwww.stern.nyuedu/ adamodar/pdfiles/papers/returnmeasures.pdf tanggal 26 Juni 2017

Damodaran, A. 2014. Corporate Finance: Theory and Practice. 2nd edition. United Sates of America: Jhon Wiley \& Sons.

Ehrhardt, M. C dan Brigham, E. F. 2011. Financial Management: Theory and Practice. $13^{\text {th }}$ edition. Mason: South-Western Chengage Learning

Gujarati, D. N, dan Porter, D. C. 2009. Basic Econometrics. $5^{\text {th }}$ edition. New York: McGraw-Hill/Irwin

Hoang, T. V. 2015. Impact of Working Capital Management on Firm Profitability: The Case of Listed Manufacturing Firms on Ho Chi Minh Stock Exchange. Asian Economic and Financial Review. 5(5): 779-789

Horne, V. dan Wachowicz, Jr. 2012. Fundamentals of Financial Management. 13th edition. Harlow: Pearson Education Limited

Jahfer, A. 2015. Effects of Working Capital Management on Firm Profitability: Empirical Evidence from Sri Lanka. International Journal of Managerial and Financial Accounting. 7(1): 26-37

Javid, S. 2014. Effect of Working Capital Management on SME's Performance in Pakistan. European Journal of Business and Management. 6(12): 206-220

Kaddumi, T. A. dan Ramadan, I. Z. 2012. Profitability and Working Capital Management : The Jordanian Case. International Journal of Economics and Finance. 4(4): 217-226

Kasmir. 2016. Pengantar Manajemen Keuangan. Edisi kedua, cetakan kelima. Jakarta: Prenadamedia Group

Konak, F dan Güner, E. N. 2016. The Impact of Working Capital Management on Firm Performance: An Empirical Evidence from the BIST SME Industrial Index. International Journal of Trade, Economics and Finance. 7(2): 38-43

Kroes, J. R dan Manikas, A. S. 2014. Cash Flow Management and Manufacturing Firm Financial Performance: A Longitudinal Perspective. International Journal Production Economics. 148: 37-50

Lavasani, H., Jabbari, H, dan Rahmani, H. 2016. Studying the Effect of Cash Flows' Management on Firm Performance in Companies Enlisted in Tehran Stock Exchange. UCT Journal of Management and Accounting Studies. 4(3): $32-37$

Mauboussin, M. J dan Callahan. 2014. Calculating Return on Invested Capital, How to Determine ROIC and Address Common Issues. diunduh di https://research-doc.credit-

suisse.com/docView?language $=E N G \&$ format $=P D F \&$ source_id=csplusresea 
rchcp\&document_id=806230540\&serialid=C0owv4XbV7zL\%2BTQLggW qjPthH7IUpSwUZpiIwdvDgtA\%3D tanggal 26 Juni 2017

Moghadam, A dan Rahimi, M. 2016. The Relationship between Working Capital Management and Cash Flows on the Financial Performance of Manufacturing Firms. Asian Journal of Research in Banking and Finance. 6(6): $34-42$

Mohamad, N. E. A dan Saad, N. M. 2010. Working Capital Management: The Effect of Market Valuation and Profitability in Malaysia. International Journal of Business and Management. 5(11): 140-147

Mwangi, L. W., Makau, M. S, dan Kosimbei, G. 2014. Effects of Working Capital Management on Performance of Non Financial Companies Listed in NSE, Kenya. European Journal of Business and Management. 6(11): 195-205

Ngendakumana, L., Jagero, N, dan Gondo, F. 2015. The Impact of Working Capital Management on the Profitability of Smart Bags Limited Manufacturing Firm in Zimbabwe. British Journal of Economics, Management \& Trade. 6 (2): 102-111

Nur, H. B., Indrawati, K, dan Ratnawati, K. Pengaruh Manajemen Modal Kerja terhadap Profitabilitas Perusahaan Non Keuangan yang Terdaftar di Bursa Efek Indonesia. Wacana. 19( 2): 82-91

Palepu, K. G, dan Healy. P. M. 2008. Business and Valuation: Using Financial Statement. $4^{\text {th }}$ edition. Canada: Thomson South-Western

Puraghajan, A., Ramzani. A. A, dan Issa, E. B. 2014. Effects of Aggressive Working Capital on the Performance of Listed Companies in Tehran Stock. Kuwait Chapter of Arabian Journal of Business and Management Review. 3(7): 71-84

Rais, H. 2016. Pengaruh Struktur Modal dan Pengelolaan Modal Kerja terhadap Profitabilitas Perusahaan di Daftar Efek Syariah Indonesia. Conference Proceedings-ARICIS I: 250-256

Rehn, E. 2012. Effects of Working Capital Management on Company Profitability, An industry-wise study of Finnish and Swedish Public Companies. Thesis. Helsinki: Department of Accounting, Hanken School of Economics

Shahzad, F., Fareed, Z, dan Zulfiqar, B. 2015. Impact of Working Capital Management on Firm 's Profitability: A Case Study of Cement Industry of Pakistan. Academic Publishing House Researcher. 91(2): 86-93

Schembs, J. 2013. The Relationship Between Growth and Value : Capital has A Cost; Ignoring It can Lead to Value Erosion. diunduh di http://www.zacharyscott.com/blog/blog/uncategorized/the-relationshipbetween-growth-and-value tanggal 26 Juni 2017

Shin, H.H dan Soenen, L. 1998. Efficiency of Working Capital Management and Corporate Profitability. Financial Planning and Education. 8(2): 37-45

Shubita, M. F. 2013. Working Capital Management and Profitability: A Case of Industrial Jordanian Companies. International Journal of Business and Social Science. 4(8): 108-115 
Sudiyatno, B., Puspitasari, E, dan Sudarsi, S. 2017. Working Capital, Firm Performance, and Firm Value: An Empirical Study in Manufacturing Industry on Indonesia Stock Exchange. Economics World. 5(5): 444-450

Tahir, M. dan Anuar. M. B. A. 2016. The Determinants of Working Capital Management and Firms Performance of Textile Sector in Pakistan. Quality \& Quantity. 50: 605-618

Tufail, S. 2013. Impact of Working Capital Management on Profitability of Textile Sector of Pakistan. Proceedings of 3rd International Conference on Business Management. Hal. 1-29

Vahid, T. K., Elham, G., Mohsen, A. K, dan Mohammadreza, E. 2012. Working Capital Management and Corporate Performance: Evidence from Iranian Companies". Procedia - Social and Behavioral Sciences. 62: 1313 - 1318

Vernimmen, P., Quiry, P., Dallocchio, M., Fur, Y. L, dan Salvi, A. 2014. Corporate Finance : Theory and Practice. Chichester: John Wiley \& Sons Ltd

Wijaya, A. L. 2012. Pengaruh Komponen Working Capital terhadap Profitabilitas Perusahaan. Jurnal Dinamika Akuntansi. 4(1): 21-26

Yadav, C. S dan Kumar S.B. S. S. 2014. Impact of Profitability on the Determinants of Working Capital: An Evident Study of Large Steel Manufacturing Companies in India. Asia Pacific Journal of Research. 1(11): 34-46.

Yakubu, I. N., Alhassan, M. M, dan Fuseini, A. A. 2017. The Impact of Working Capital Management on Corporate Performance: Evidence from Listed Non-Financial Firms in Ghana. European Journal of Accounting, Auditing and Finance Research. 5(3): 68-75

Yilmaz, I. 2015. The Interaction Of Working Capital Management and Profitability Measures. Finansal Araştırmalar ve Çalışmalar Dergisi. 7(13): 437-448

Zeidan, R dan Shapir, O. M. 2017. Cash Conversion Cycle and Value-enhancing Operations: Theory and Evidence for a Free Lunch. Journal of Corporate Finance. 45: 203-219 